Research Article

\title{
A comparative prospective study to assess the clinical efficacy and safety of pantoprazole monotherapy versus pantoprazole and itopride dual therapy in patients with gastroesophageal reflux disease in a tertiary care hospital
}

\author{
Pradeep Kumar $\mathrm{BT}^{1} *$, Mamatha $\mathrm{KR}^{2}$, Nagesh $\mathrm{NS}^{3}$, Jayanthi $\mathrm{CR}^{2}$, Bharath Kumar VD ${ }^{2}$
}

\begin{abstract}
${ }^{1}$ Department of Pharmacology, Annapoorana Medical College and Hospital, Salem, Tamil Nadu, India ${ }^{2}$ Department of Pharmacology, ${ }^{3}$ Department of Surgical Gastroenterology, Bangalore Medical College and Research institute, Bangalore, India
\end{abstract}

Received: 26 June 2016 Accepted: 05 August 2016

*Correspondence to: Dr. Pradeepkumar BT, Email: pradeepkumar6@gmail.com

Copyright: () the author(s), publisher and licensee Medip Academy. This is an open-access article distributed under the terms of the Creative Commons Attribution Non-Commercial License, which permits unrestricted non-commercial use, distribution, and reproduction in any medium, provided the original work is properly cited.

\section{ABSTRACT}

Background: Gastroesophageal reflux disease (GERD) is a common chronic, relapsing condition that carries a risk of significant morbidity and potential mortality from resultant complications. Proton pump inhibitors (PPIs) remained as the main stay in the therapy of GERD but they do not have any role in increasing the tone of lower esophageal sphincter which is the main pathophysiology of GERD. In this regard addition of prokinetic agent like Itopride may be beneficial in improving the symptoms associated with GERD. So the present study has been taken to compare the healing rates of esophagitis and reduction in symptom scores associated with GERD between Pantoprazole monotherapy and Pantoprazole plus Itopride combination.

Methods: 100 patients diagnosed with GERD were randomly assigned into two groups, Group A and Group B. Group A received tablet Pantoprazole $40 \mathrm{mg}$ twice daily alone and group B received tablet Pantoprazole $40 \mathrm{mg}$ twice daily and tablet Itopride $50 \mathrm{mg}$ thrice daily 30 minutes before food for 4 weeks. The patients were followed up at the end of 4 weeks and were given the questionnaire to assess the FSSG scores. Endoscopy and FSSG scores were recorded and then the percentage of responders in both groups was compared.

Results: Endoscopic evidence of healing of esophagitis was similar in both the groups, $72 \%$ in Group A and $74 \%$ in Group B. The symptom relief was significantly more in Pantaprozole plus Itopride group $74.5 \%(4.2 \pm 1.6)$ than Pantaprozole alone $62.5 \%(6.4 \pm 1.1)$ after 4 weeks ( $p<0.001)$.The occurrence of side effects was less in group B compared to group A $(22 \%$ vs $30 \%$, p= 0.172).

Conclusions: Pantoprazole and combination of Pantoprazole plus Itopride provide more effective endoscopic healing of esophagitis. Pantoprazole and Itopride combination is more efficacious in ameliorating the symptoms of GERD than Pantoprazole alone.

Keywords: Pantoprazole, GERD, LES, Itopride, PPIs, Prokinetics, Esophagitis, FSSG scores

\section{INTRODUCTION}

Gastroesophageal reflux disease (GERD) is a condition characterized by reflux of acid gastric contents into the esophagus, with attendant inflammation, irritation and often with erosive damage to the esophageal mucosa. ${ }^{1}$ The prevalence of GERD ranges from $10 \%$ to $30 \%$ in the western population and $18.7 \%$ in Indian population. ${ }^{2,3}$

Although most cases follow a relatively benign course, GERD in some individuals can cause severe erosive esophagitis and serious sequelae includes stricture formation and Barrett's metaplasia (replacement of squamous by intestinal columnar epithelium), which in turn, is associated with a small but significant risk of adenocarcinoma ${ }^{4}$.

Pathogenesis of GERD is lower esophageal sphincter (LES) dysfunction, abnormal clearing capacity of refluxed materials, delayed gastric emptying and abnormal resistance of esophageal mucosa to gastric acid, but the primary motor dysfunction is regarded as the most important factor in general $^{5,6}$.

The most common presentation of patients with GERD includes a long-standing history of heartburn and a 
shorter history of regurgitation. Heartburn, when typical, is a very reliable symptom. Heartburn is confined to the epigastric and retrosternal areas. Somewhat less common is dysphagia and chest pain. Sometimes these symptoms are disabling and require treatment.

The goals of GERD therapy are complete resolution of symptoms and healing of esophagitis. Proton pump inhibitors clearly are more effective than H2-receptor antagonists in achieving these goals. ${ }^{7}$ Healing rates after 4 weeks and 8 weeks of therapy with proton pump inhibitors are approximately $80 \%$ and $90 \%$ respectively, while the corresponding healing rates with $\mathrm{H}_{2}$-receptor antagonists are $50 \%$ and $75 \%$ respectively. ${ }^{7}$

Proton pump inhibitors (PPIs) have been accepted as the first line treatment of GERD because of greater efficacy and faster healing rate. ${ }^{8}$ PPIs like Pantoprazole cause decrease in acid production and have high healing rates and rates of resolution of reflux symptoms at 4 weeks, but they do not help to improve underlying disturbance in gut motility or improve the tone of cardiac sphincter. ${ }^{9}$

Itopride, a novel gastro prokinetic agent stimulates gastrointestinal motor activity through dual mode of action, acting as dopamine $\mathrm{D}_{2}$ receptor antagonist and cholinesterase inhibitor. It has an antiemetic action, accelerates gastric emptying and modulates gastric sensorimotor function. ${ }^{10}$

The combination is synergistic by decreasing acid production as well as increasing lower esophageal sphincter tone and esophageal clearance, thus providing a better therapeutic response.

In view of problems with tolerability with other prokinetic drugs, also there is paucity of literature with combination of Pantoprazole and Itopride in GERD, the present study has been taken up.

\section{METHODS}

This was a prospective, comparative, randomized study. It was conducted on outpatients attending the department of surgical gastroenterology, Victoria hospital, Bangalore. The present study was undertaken after approval from institutional ethics committee.

100 patients of either sex aged between 18-60 years, more than one upper dyspeptic symptoms such as regurgitation, epigastric pain, nausea, vomiting, dysphagia, chest pain lasting for more than 4 weeks, frequency scale for the symptoms of GERD (FSSG) score $>8$, grade I-III esophagitis by modified Savary-Miller classification by endoscopic examination were included in the study after taking written informed consent from the patients.

Exclusion criteria were corrosive esophagitis by a toxicant, esophagitis due to inflammatory, infection or radiotherapy, regular use of $\mathrm{H}_{2}$ blockers, prokinetic or anticholinergic agents for previous 4 weeks, previous gastrointestinal surgery, inflammatory bowel disease, cardiological, respiratory, gastrointestinal disease, endocrine metabolic disease and neuro-psychological disease, clinically significant hepatic or renal dysfunction, pregnant and lactating women.

The patients were randomly assigned into two treatment groups.

- Group A: received tablet Pantoprazole $40 \mathrm{mg}$ twice daily alone 30 minutes before food for 4 weeks.

- Group B: received tablet Pantoprazole $40 \mathrm{mg}$ twice daily and tablet Itopride $50 \mathrm{mg}$ thrice daily 30 minutes before food for 4 weeks.

Both the groups were also advised to avoid alcohol and smoking during the study period. Patients were advised to come for follow up after 4 weeks, endoscopy and FSSG scores were again recorded and those patients who showed Improvement in FSSG scores and endoscopic healing of esophagitis were considered responders and then the percentage of responders in both groups were compared.

Efficacy parameters were: improvement in FSSG scores and endoscopic healing of esophagitis (completely curedany grade of esophagitis improving to grade 0 , partially cured-improving at least one grade lower from baseline, not cured- remaining at the same grade as baseline).

Safety parameters were: occurrence of adverse drug reactions after treatment, changes in laboratory tests.

\section{Statistical analysis}

Parametric variables were analysed using student $t$ test and $\mathrm{z}$ test. Non-parametric variables were analysed using Fischer exact test and Chi- square test.

\section{RESULTS}

The present study was done at Victoria hospital, department of surgical gastroenterology, Bangalore medical college and research institute revealed the following results. Totally 100 patients suffering from GERD were evaluated for efficacy and safety. All the 100 patients completed the study and there were no drop outs.

In the present study both the treatment groups matched with respect to age, gender, diet, habits, co-morbid conditions and area of distribution.

At the end of 4 weeks of treatment 73 cases ( 36 cases in Group A and 37 in the Group B) were cured. 18 patients (9 in each group) showed partial healing. 9 patients $(5$ in Group $\mathrm{A}$ and 4 in Group B) did not show any improvement in healing of esophagitis as shown in Figure1. Although the healing of esophagitis is similar in 
both the treatment groups but there is no statistical significance with the $\mathrm{p}=0.639$.

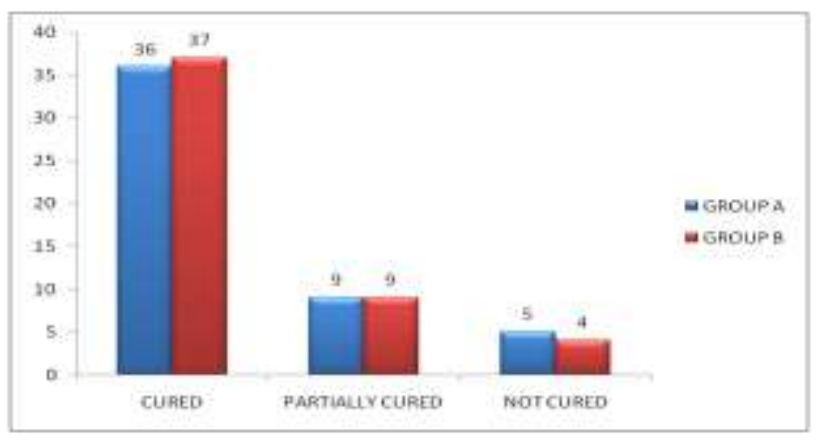

Figure 1: Comparison of healing rates of esophagitis in two groups at the end of 4 weeks.

The mean symptom score before treatment in Group A was $17.1 \pm 1.6$ and in Group B was $16.8 \pm 1.6$. The mean change in symptom score after treatment in Group A was $6.4 \pm 1.1$ and in the Group B was $4.2 \pm 1.6$ as given in Figure 2. There was statistically significant in overall reduction in symptom score in Group B $(74.5 \pm 9.8)$ when compared to Group A $(62.5 \pm 6.2)$ with the $\mathrm{p}<0.001$.

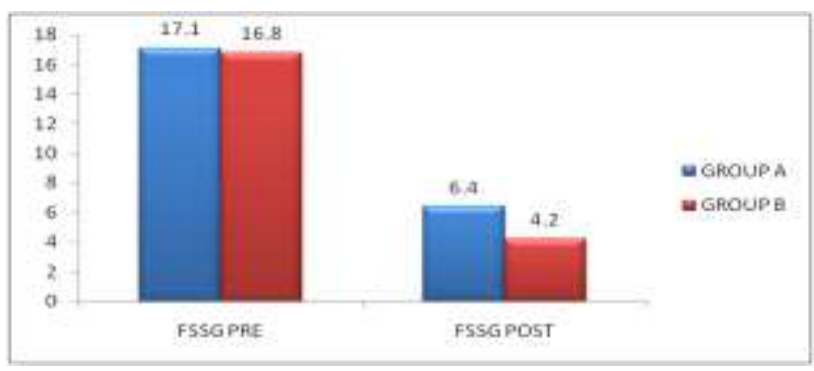

Figure 2: Comparison of FSSG score between two groups.

The following side effects were reported in Group A and Group B such as nausea, abdominal pain, diarrhoea and headache as in Figure 3. Occurrence of side effects were less in Group B but was not statistically significant $(\mathrm{p}=0.495)$ as shown in Figure 3.

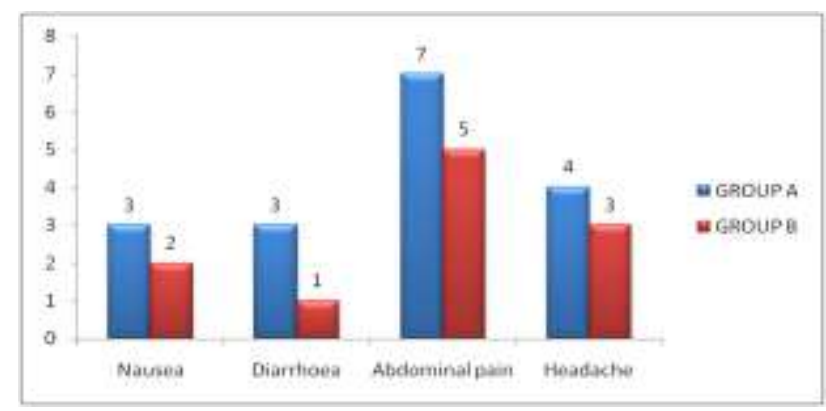

Figure 3: Comparison of side effects between two groups at the end of 4 weeks.
There was no change in laboratory parameters in both the groups at $4^{\text {th }}$ week compared to baseline as presented in Table 4.

Table 4: Comparison of laboratory parameters in two groups of patients studied.

\begin{tabular}{|c|c|c|}
\hline $\begin{array}{l}\text { Laboratory } \\
\text { parameters }\end{array}$ & Group A & Group B \\
\hline \multicolumn{3}{|l|}{ Hb (mg/dl) } \\
\hline Baseline & $12.19 \pm 1.54$ & $12.15 \pm 1.54$ \\
\hline End of study & $12.32 \pm 1.34$ & $12.28 \pm 1.33$ \\
\hline \multicolumn{3}{|c|}{ Random blood sugar (mg/dl) } \\
\hline Baseline & $101.46 \pm 7.91$ & $91.80 \pm 15.47$ \\
\hline End of study & $100.84 \pm 9.66$ & $91.26 \pm 16.02$ \\
\hline \multicolumn{3}{|c|}{ Blood urea (mg/dl) } \\
\hline Baseline & $26.90 \pm 5.04$ & $26.96 \pm 5.24$ \\
\hline End of study & $26.86 \pm 5.22$ & $26.28 \pm 4.65$ \\
\hline \multicolumn{3}{|c|}{ Serum creatinine } \\
\hline Baseline & $0.84 \pm 0.16$ & $0.56 \pm 0.19$ \\
\hline End of study & $0.80 \pm 0.13$ & $0.62 \pm 0.18$ \\
\hline \multicolumn{3}{|l|}{ SGOT (in IU) } \\
\hline Baseline & $26.70 \pm 5.14$ & $26.48 \pm 5.03$ \\
\hline End of study & $25.60 \pm 4.59$ & $25.80 \pm 4.69$ \\
\hline \multicolumn{3}{|l|}{ SGPT(in IU) } \\
\hline Baseline & $25.42 \pm 6.24$ & $25.14 \pm 6.38$ \\
\hline End of study & $24.56 \pm 5.63$ & $24.10 \pm 5.42$ \\
\hline
\end{tabular}

\section{DISCUSSION}

Gastroesophageal reflux disease (GERD), a common disorder with troublesome symptoms caused by reflux of gastric contents into the esophagus and its prevalence is increasing worldwide.

It usually manifests as heartburn, regurgitation, or dysphagia, and predisposes to development of esophagitis, stricture, Barrett's metaplasia, and a substantial decreased in the quality of life. GERD is a risk factor for the development of esophageal adenocarcinoma, further increasing the importance of its diagnosis and treatment.

A variety of medications have been used in GERD treatment, and acid suppression therapy is the mainstay of treatment for GERD. Although proton pump inhibitor is the most potent acid suppressant and provides good efficacy in esophagitis healing and symptom relief, about one-third of patients with GERD still have persistent symptoms with poor response to standard dose of PPI. Antacids, alginate, histamine type- 2 receptor antagonists, and prokinetic agents are usually used as add-on therapy to PPI in clinical practice.

Development of novel therapeutic agents has focused on the underlying mechanisms of GERD, such as transient lower esophageal sphincter relaxation, motility disorder, mucosal protection, and esophageal hypersensitivity. 
In this regard addition of a prokinetic agent like Itopride along with PPI like pantoprazole, results in complete resolution of dyspeptic symptoms and improvement in the quality of life.

In the present study endoscopic healing of esophagitis was seen equally in both the groups, Group A $72 \%$ $(36 / 50)$, and $74 \%(37 / 50)$ in Group $\mathrm{B}, \mathrm{p}=0.639$. Overall $73 \%$ of the patients were completely cured while $18 \%$ patients had partial healing in both the treatment groups.

This result was similar to the comparative study by Singhal et al who reported complete curing rate of $72.34 \%$ while the partial curing rate of $20.21 \%$ with Pantoprazole and domperidone. ${ }^{11}$ Another study by Madan et al had showed the healing rates of $70.5 \%$ with pantoprazole and mosapride when compared to pantoprazole alone. $^{12}$

Pantaprozole alone and combination of Pantaprozole with Itopride showed a significant reduction in symptom score independently. The symptom relief was significantly more in Pantaprozole plus Itopride group $74.5 \%$ (4.2 \pm 1.6$)$ than Pantaprozole alone $62.5 \%(6.4 \pm 1.1)$ after 4 weeks ( $\mathrm{p}<0.001)$.This was similar to the pilot study by Krishnakant et al who reported the symptom relief was 74\% with Pantoprazole plus Itopride and 70\% when compared to pantoprazole alone. ${ }^{13}$

A study by Kim YS et al showed that Itopride $100 \mathrm{mg}$ three times a day improved GERD symptoms and decreased esophageal acid exposure. ${ }^{4}$ Another study, by Vigneri et al showed the response rate in the combination group of omeprazole and cisapride was higher than in patients who received omeprazole alone. ${ }^{14}$ There was symptomatic improvement after adding itopride with pantoprazole, this improvement did not match the endoscopic healing. This is not surprising as it is well known that endoscopic healing does not correlate with symptomatic improvement as per the study done by Robinson et al. ${ }^{15}$

Addition of a prokinetic agent like Itopride $\mathrm{D}_{2}$ antagonist with anticholinesterase activity causes significant improvement of pathogenic mechanism of GERD such as gastrointestinal motility disorder, incompetent LES relaxation, impaired esophageal acid clearance, and prolonged gastric emptying which in turn results in the symptomatic improvement in patients of GERD.

$26 \%$ patients experienced side effects, 30\% in Group A and $22 \%$ in Group B. Diarrhoea (4\%), abdominal pain $(12 \%)$ and headache $(7 \%)$ were the common side effects seen in both the groups and are of mild severity. Incidence of abdominal pain, headache and diarrhoea were the most common side effect in the Group A, whereas abdominal pain was seen more frequently in the Group B. But there is no statistically significant difference seen between both the groups $(p=0.495)$.
In a study conducted by Bochenek et al has reported the incidence of adverse effects $11 \%$ headache, $7 \%$ diarrhoea with pantoprazole. ${ }^{16}$ Another study by Vigneri et al had reported the adverse effects like diarrhoea, abdominal cramps, flatulence with the Pantoprazole and Mosapride and they were of mild type and most of them disappeared spontaneously. ${ }^{14}$

\section{CONCLUSION}

The present study demonstrated that both Pantoprazole and combination Pantoprazole plus Itopride provide more effective healing of esophagitis as evidenced by the endoscopic examination before and after treatment. In terms of efficacy the combination of Pantoprazole and Itopride is more efficacious in ameliorating the symptoms of GERD as evidenced by the significant reduction in the FSSG symptom score than Pantoprazole alone at the end of 4 weeks of treatment.

\section{ACKNOWLEDGEMENTS}

The authors would like to thank all the staff, department of pharmacology, Bangalore Medical College and Research Institute, Bangalore, for their constant support and guidance and also HOD and staff of department of surgical gastroenterology for their valuable support in making the study successful.

Funding: No funding sources

Conflict of interest: None declared

Ethical approval: The study was approved by the Institutional Ethics Committee

\section{REFERENCES}

1. Dekkers CP, Beker JA, Thjodleifsson B, Gabryelewicz A, Bell NE, Humphries TJ. Doubleblind, placebo-controlled comparison of rabeprazole $20 \mathrm{mg}$ vs omeprazole $20 \mathrm{mg}$ in the treatment of erosive or ulcerative gastro-oesophageal reflux disease. Aliment Pharmacol Ther. 1999;13:49-57.

2. Holtmann G. Reflux disease: the disorder of the third millennium. Eur J Gastroenterol Hepatol. 2001;13(1):5-11.

3. Kumar S, Sharma S, Norboo T, Dolma D, Norboo A, Stobdan T, et al. Population based study to assess prevalence and risk factors of gastroesophageal reflux disease in high altitude area. Indian society of Gastroenterology. 2010;30(3):135-43.

4. Kim YS, Kim TH, Choi CS, Shon YW, Kim SW, Seo GS, et al.Effect of itopride new prokinetic in patients with mild GERD: A pilot study. World J Gastroenterology. 2005;11(27):4210-4.

5. Lundell L, Myers JC, Jamieson GG. Is motility impaired in the entire upper gastrointestinal tract in patients with gastrooesophageal reflux disease? Scand J Gastroenterol. 1996;31:131-5.

6. $\quad$ Rydberg L, Ruth M, Lundell L. Does oesophageal motor function improve with time after successful 
antireflux surgery? Results of a prospective, randomized clinical study. Gut. 1997;41:82-6.

7. Hoogerwerf WA, Pasricha PJ. Pharmacotherapy of gastric acidity, peptic ulcers and gastroesophageal reflux disease. In: Brunton LL, Lazo JS, Parker KL, eds. Goodman and Gillman's The Pharmacological Basis of Therapeutics.11th ed. New York, McGraw hill; 2006: 1309-1322.

8. Chandrasoma P. The Pathology of Gastroesophageal Reflux Disease. In: Yeo CJ, Dempesy DT, Klein AS, Pemberton JH, Peters JH, Eds. Shackelford's Surgery of the Alimentary Tract. 6th ed. Elsevier; 2012: 560-580.

9. Modlin IM, Borteçen KH, Sandor A, et al. Solving the GORDian knot. In: Büchler MW, Frei E, Klaiber $\mathrm{Ch}$, et al. eds. Gastroesophageal reflux disease (GERD): back to surgery? Basel, Switzerland. Karger; 1997: 60-70.

10. Scarpellini E, Vos R, Blondeau K, Boecxstaens V, Boecxstaens V, Farré R, Gasbarrini A, et al. The effect of itopride on oesophageal motility and lower oesophageal sphincter function in man. Aliment Pharmacol and Ther. 2011;33:99-105.

11. Singhal S, Dhawan P, Bhatt A, Pokharna R, Sharma D, Kumar G, et al. Evaluation of Safety and Efficacy of Pantoprazole and Domperidone Combination in Patients with Gastroesophageal Reflux Disease. The Internet Journal of Gastroenterology. 2006;4(2):1-5.

12. Madan K, Ahuja V, Kashyap PC, Sharma MP. Comparison of efficacy of pantoprazole alone versus pantoprazole plus mosapride in therapy of gastroesophageal reflux disease: a randomized trial. Dis Esophagus. 2004;17:274-8.

13. Krishnakanth K, Siddalingappa CM, Kudagi BL. Efficacy of pantaprozole versus pantaprozole plus itopride in gastroesophageal reflux disease patients A pilot study. Indian journal of Pharmacology. 2011;43:205-8

14. Vigneri S, Termini R, Leandro G, Badalamenti S, Pantalena M, Savarino V, et al. A comparison of five maintenance therapies for reflux esophagitis. $\mathrm{N}$ Eng J Med. 1995;333:1106-10.

15. Robinson MG, Orr WC, McCallum R, Nardi R. Do endoscopic findings influence response to $\mathrm{H} 2$ antagonist therapy for gastroesophageal reflux disease. Am J Gastroenterol. 1987;82:519-22.

16. Bochenek WJ, Mack ME, Fraga PD and Metz DC. Pantoprazole provides rapid and sustained symptomatic relief in patients treated for erosive oesophagitis. Aliment Pharmacol Ther. 2004;20:1105-14.

Cite this article as: Pradeep kumar BT, Mamatha KR, Nagesh NS, Jayanthi CR, Bharath kumar VD. A comparative prospective study to assess the clinical efficacy and safety of pantoprazole monotherapy versus pantoprazole and itopride dual therapy in patients with gastroesophageal reflux disease in a tertiary care hospital. Int J Basic Clin Pharmacol 2016;5:1953-7. 